\title{
Endovideosurgery in CF «UMC» NRCMC: achievements and prospects
}

\author{
Damir Jenalayev ${ }^{1}$, Dulat Mustafinov ${ }^{1}$,
${ }^{I}$ Corporate Fund «University Medical Center» National \\ Research Center for Maternal and Child Health
}

This work is licensed under a Creative Commons Attribution 4.0 International License

J CLIN MED KAZ 2017; 3(45 SUPPL 3):133-135 Corresponding author: Дженалаев Дамир Булатович, д.м.н., руководитель отдела детской хирургии Корпоративного фонда «University Medical Center «Национальный научный центр материнства и детства», тел: 8(701) 522-12-89,

e-mail-damir1972@mail.ru

\section{ABSTRACT}

The article shows the experience of performing endovideosurgical operations in children. The experience of performing operations in various sections of pediatric surgery are presented: thoracic surgery, abdominal surgery, urology, orthopedics and vertebrology.

Key words: laparoscopy, thoracoscopy, children.

ТҰЖЫРЫМДАМА

АНА МЕН БАЛА ОРТАЛЫҒЫНДА ЭНДОБЕЙНЕХИРУРГИЯЛЫК: ЖЕТІСТІКТЕРІ МЕН КЕЛЕШЕГІ

Женалаев Д.Б. ${ }^{1}$, Мұстафинов Д.А. ${ }^{1}$, Мамлин О.А. ${ }^{1}$, Біләл Р.Ә. ${ }^{1}$

${ }_{1}$ «University Medical Center» корпоративтік қорының Ана мен бала ұлттық ғылыми орталығы

Мақалада балалардағы эндовидеохирургиялық операцияларды орындау тәжірибесі көрсетілген. Педиатриялық хирургияның әртүрлі бағыттарында операцияларды орындау тәжірибесі: торакальды хирургия, абдоминальді хирургия, урология, ортопедия және вертебрология.

Маңызды сөздер: лапароскопия, торакоскопия, балалар.

PE3ЮME

ДОСТИЖЕНИЯ И ПЕРСПЕКТИВЫ ЭНДОВИДЕОХИРУРГИИ В НАЦИОНАЛЬНОМ НАУЧНОМ ЦЕНТРЕ МАТЕРИНСТВА И ДЕТСТВА

Дженалаев Д.Б. ${ }^{1}$, Мустафинов Д.А. ${ }^{1}$, Мамлин О.А. ${ }^{1}$, Билал Р.А. ${ }^{1}$

'Корпоративный фонд «University Medical Center «Национальный научный центр материнства и детства»

В статье приведен опыт выполнения эндовидеохирургических операций у детей. Представлен опыт выполнения операций в различных разделах детской хирургии: торакальная хирургия, абдоминальная хирургия, урология, ортопедия и вертебрология.

Ключевые слова: лапароскопия, торакоскопия, дети.

\section{Kipicne}

Стремление к выполнению максимально щадящих операций привело к созданию революционно нового направления в современной хирургии - лапароскопической хирургии. Конец 80-х, начало 90-х годов прошедшего столетия был ознаменован бурным развитием лапароскопической хирургии и развитием её как самостоятельного направления в медицинской науке, коренным образом изменившее облик современной хирургии $(1,2,3)$.

В настоящее время эндовидеохирургия заняла прочные позиции во многих отраслях хирургии $(4,5)$. Эндоскопическая хирургия все активнее внедряется в клиническую практику хирургических стационаров, увеличивается количество клиник, имеющих специальное эндохирургическое оборудование.

Одним из приоритетных направлений филиала корпоративного фонда ««University Medical Center» «Национальный научный центр материнства и детства» является активное внедрение в клиническую практику малоинвазивных методов лечения, к числу которых относится и эндовидеохирургия.
В настоящее время в отделе детской хирургии, включающем в себя отделения детской хирургии, ортопедии и вертебрологии, урологии, нефрологии и диализа, доля малоинвазивных оперативных вмешательств составляет около 20\% (в 2016 году выполнено около 4000 операций).

Перечень оперативных вмешательств, выполняемых в ННЦМД.

Абдоминальная хирургия

- Герниорафия при паховых грыжах

- Эхинококкэктомия при эхинококковых кистах печени, селезенки, брюшной полости

- Холецистэктомия при ЖКБ, хроническом калькулезном холецистите

- Лапароскопическая коррекция ГПОД

- Лапароскопическая коррекция кист общего желчного протока

- Лапароскопическая спленэктомия

- Лапароскопическое иссечение кист брюшной полости

- Операция К. Georgeson при болезни Гиршпрунга

Лапароскопические операции при паховых грыжах - в настоящее время мы используем в своей практике следующие методики при оперативном лечении паховых 
грыж: наложение кисетного шва на внутреннее паховое кольцо, пластика с использованием сетчатого трансплантата и методику PIRS. Конверсии к открытому вмешательству и рецидивов в наших наблюдениях не отмечалось.

\section{Лапароскопическая эхинококкэктомия печени}

методика лапароскопической эхинококкэктомии заключается в пункции кисты, обеззараживании полости кисты, вскрытии кисты и удаления хитиновой оболочки и остаточной жидкости путем вакуум-экстракции, абдоминизации остаточной полости путем иссечения части фиброзной капсулы капсулы и дренирования остаточных полостей и подпеченочного пространства. У некоторых пациентов в операция заканчивалась катетеризацией круглой связки печени по Сельдингеру для проведения в послеоперационном периоде регионарной лимфотропной терапии. Необходимо отметить, что только в единичных случаях нам пришлось прибегнуть к конверсии.

Лапароскопическая холецистэктомия - в отличие от взрослого населения данная операция в детском возрасте является достаточно редкой, в год у нас выполняется не более 2-3 холецистэктомий. Хотелось бы отметить, что за последние 5 лет нами отмечено два осложнения после лапароскопической холецистэктомии (длительное желчеистечение из зоны оперативного вмешательства), которые купировались консервативно.

Лапароскопия в колопроктологии детского возраста

Хирургические вмешательства в колопроктологии характеризуются, как правило, высокой травматичностью, тяжелым послеоперационным и длительным восстановительными периодами. Развитие медицинской науки расширило возможности использования эндовидеохирургических методов коррекции заболеваний и обусловило предпосылки к их использованию в колопроктологической практике $(6,7,8)$.

Мы располагаем 21 наблюдением лапароскопическиассистированных операций при болезни Гиршпрунга у детей. Наши наблюдения позволяют сделать вывод, что лапароскопическая операция по К.Georgeson сочетает в себе радикальность и минимальную травматичность и позволяет добиться существенного улучшения результатов лечения.

\section{Лапароскопическое иссечение кисты холедоха}

Проблема лечения кистозных трансформаций желчевыводящих путей у детей остается актуальной до настоящего времени $(9,10)$.

В лечении 9 пациентов нами были использованы методы эндовидеохирургии (основная группа). Этим пациентам производили лапароскопическое иссечение кистозно-измененных желчных ходов с формированием гепатикоэнтероанастомоза по Ру. В первых двух случаях выполняли лапароскопически ассистированную операцию, при которой один из этапов (формирование межкишечного анастомоза по Ру) выполняли экстракорпорально, через дугообразно расширенный разрез в пупке. В остальных случаях все этапы операции были выполнены полностью лапароскопическим способом.

Интра и послеоперационных осложнений в наших наблюдениях не отмечалось.

Эндовидеохирургия в детской урологии

- Лапароскопическая коррекция варикоцеле

- Лапароскопические операции при крипторхизме

- Лапароскопические операции при мочекаменной болезни
- Лапароскопическая нефруретерэктомия

- Лапароскопическая пластика гидронефроза у детей

Лапароскопическая пластика пиелоуретрального сегмента при гидронефрозе

Нами выполнено около 30 лапароскопических операций при гидронефрозе: при этом в 21 случае нами выполнялась лапароскопически-ассистированная операция, при которой лапароскопически выделялся пиелоуретральный сегмент, который выводился на переднюю брюшную стенку через мини-доступ для проведения непосредственно пластики; в 9 случаях операция выполнялась полностью лапароскопически.

Лапароскопические операции при мочекаменной болезни.

При мочекаменной болезни лапароскопия была успешно была применена у 2-х пациентов. У первого пациента с камнем средней трети правого мочеточника после вскрытия брюшины выполнена лапароскопическая уретеролитотомия, у второго пациента после безуспешной попытки извлечения камня мочевого пузыря при помощи уретроцистоскопа и корзинки Дормия под контролем цистоскопа внебрюшинно введен 5 мм троакар и с помощью жесткого зажима произведено извлечение конкремента.

Торакальная эндовидеохирургия

- Торакоскопическая пластика диафрагмальной грыжи

- Торакоскопическая коррекция атрезии пищевода

- Торакоскопическая эхинококкэктомия легких и грудной клетки

- Торакоскопическая резекция легких

- Видеоассистированная операция по Насса при воронкообразной грудной клетке

Внедрениев клиническуюпрактикулапароскопической хирургии способствовало интенсивному развитию торакоскопии.

Торакоскопическая коррекция диафрагмальной грыюжи у детей

Хирургическое лечение детей с врожденными диафрагмальными грыжами, особенно новорожденных, остается до настоящего времени одной из сложных задач в детской хирургии. При истинной диафрагмальной грыже мы производили наложение гофрирующих швов (Ethibond 2/0) в переднезаднем направлении до полного уплощения купола диафрагмы. При ложной диафрагмальной грыже производили постепенное погружение петель кишечника и сальника под воздействием инсуффляции СО2 и при помощи эндоскопических инструментов в брюшную полость через дефект диафрагмы, после чего ушивали дефект диафрагмы отдельными швами Ethibond 2/0.

Видеоассистированная операция по Насса при воронкообразной деформации грудной клетки у детей

С января 2013 года в АО «ННЦМД» было выполнено более 200 видеоассистированных торакопластик по методике Насса при воронкообразной грудной клетке пациентам в возрасте от 3 до 17 лет. В послеоперационном периоде отмечалось значительное уменьшение болевого синдрома по сравнению с операциями, при которых проводилось пересечение реберных хрящей. Рецидивов заболевания в наших наблюдениях не отмечалось.

В настоящее время нами начаты первые шаги в применении эндовидеохирургии при атрезиях прямой кишки, атрезии желчевыводящих протоков 
(лапароскопическая операция Кассаи), вертебрологии (передний доступ при сколиозах у детей с использованием торакоскопии).

Анализ литературы и наш пока еще незначительный опыт позволяет с уверенностью утверждать, что в современной детской хирургии наметилась выраженная тенденция постепенного превращения хирургии в малоинвазивную, каковой является эндовидеохирургия. Становится очевидным, что этот процесс столь же объективен, сколь и неотвратим.

\section{Литература:}

1. Dronov A.F., Poddubnyj I.V., Kotlobovskij V.I. [in Russian]. Jendoskopicheskaja hirurgija u detej. 2002; 440s.

2. K.Slim., J.Chipponi. Laparoscopy surgery today. British Journal of Surgery.2006; 93: 779-780.

3. Kozlov Ju.A. Minimal'no invazivnaja hirurgija novorozhdennyh i detej rannego grudnogo vozrasta [in Russian]. Dissertacija d.m.n.- Irkutsk.2014; 282 s.

4. Bax NM, van der Zee DC: Laparoscopic treatment of intestinal malrotation in children. World journal of emergency surgery.2011.35:1781-1784.

5. O. G. Mokrushina, A. V. Geras'kin, N. V. Golodenko, M. V. Levitskaja, V. S. Shumihin, V. I. Derunova. Hirurgicheskie aspekty lechenija duodenal'noj neprohodimosti u novorozhdennyh. [in Russian]. Detskaja hirurgija. 2010. 6:S.8-11.

6. Liem NT, Hau BD. Primary laparoscopic endorectal colon pull-through for Hirschsprung's disease: early results of 61 cases. Asian J Surg. 2006 29(3):173-5.

7. Jacob C. Langer, MD, Audrey C. Durrant, MD, Luis de la Torre, MD, Daniel H. Teitelbaum, MD, Robert K. Minkes, MD, Michael G. Caty, MD, Barbara E. Wildhaber, MD, S Jose Ortega, MD, Shinjiro Hirose, MD, and Craig T. Albanese. One-Stage Transanal Soave Pullthrough for Hirschsprung Disease. Ann Surg. 2003 October; 238(4): 569-576.

8. De la Torre-Mondragon L, Ortega-Salgado JA. Transanal endorectal pull-through for Hirschsprung's disease. J Pediatr Surg. 1998;33:1283-1286.

9. Ahn SM, Jun JY, Lee WJ, Han SJ, Choi SH, Hwang EH. Laparoscopic total intracorporeal correction of choledochal cyst in pediatric population. Journal Laparoendos Adv Surg Tech A 2009; 19(5): 683-86.

10. LimNT, Dung le A, Son TN. Laparoscopic complete cyst excision and hepaticoduodenostomy for choledochal cyst: early results in 74 cases. Journal Laparoendos Adv Surg Tech A .2009 19(1): 87-90. 